\title{
Strong ground motions recorded by a near-source seismographic array during the 16 August 2005 Miyagi-Ken-Oki, JAPAN, earthquake (Mw 7.2)
}

\author{
Hisashi Nakahara ${ }^{1}$, Kaoru Sawazaki ${ }^{1}$, Nobumasa Takagi ${ }^{1}$, Takeshi Nishimura ${ }^{1}$, Haruo Sato ${ }^{1}$, and Hiroyuki Fujiwara ${ }^{2}$ \\ ${ }^{1}$ Department of Geophysics, Graduate School of Science, Tohoku University, Sendai 980-8578, Japan \\ ${ }^{2}$ National Research Institute for Earth Science and Disaster Prevention, Tsukuba 305-0006, Japan
}

(Received November 28, 2005; Revised May 20, 2006; Accepted June 2, 2006; Online published February 2, 2007)

\begin{abstract}
An earthquake of Mw 7.2 took place on August 16, 2005 at a plate boundary between the Pacific plate and the North American plate off the coast of Miyagi Prefecture, Northeast Japan. During the Miyagi-Ken-Oki event, we succeeded in recording strong ground motions at six stations in a seismograhic array with an epicentral distance of about $70 \mathrm{~km}$, where we have been operating seven strong-motion seismometers in an aperture of about $500 \mathrm{~m}$ since April 2004. The predominant period of the ground motion was shorter than $0.3 \mathrm{~s}$. The peak ground acceleration exceeded $1.7 \mathrm{~g}$ at a station where non-linear site response may have occurred during the mainshock. The short-period strong ground motions show a large spatial variation, with up to a ten-fold difference in amplitude even within the array. However, there is a similarity between waveforms registered at different stations for periods longer than $0.4 \mathrm{~s}$. Therefore, the difference in the ground motions may be mainly attributed to the difference in the shallow structure just beneath the stations.
\end{abstract}

Key words: Miyagi-Ken-Oki earthquake, array, strong ground motion, spatial variation, non-linear site response.

\section{Introduction}

In regions off the coast of Miyagi Prefecture, earthquakes having a magnitude $(\mathrm{M})$ of about 7.5 have repeatedly occurred with a recurrence period of about 37 years during the past 200 years. More than 27 years have passed since the last event on June 12, 1978. According to the Headquarters for Earthquake Research Promotion (HERP), the source regions of these earthquakes are identified as regions A1, A2, and B in Fig. 1, and the conditional probability of the occurrence of the next event within 30 years starting from January 1, 2005 is estimated to be $99 \%$ (HERP, 2005), probably the highest in the world.

On August 16, 2005, an earthquake of $\mathrm{Mw}=7.2$ took place at a depth of around $30 \mathrm{~km}$ on the plate boundary between the subducting Pacific plate and the North American plate. The epicenter is shown by a solid star in Fig. 1. The focal mechanism is a thrust type. The HERP judged that the event was not the expected one. The earthquake produced the largest ground motions to date with an intensity of 6 lower in the Japan Meteorological Agency scale. There were no casualties; however 11 people were seriously injured and 78 were slightly injured. At a nuclear power plant located at the base of the Oshika Peninsula, the amplitude of acceleration response spectrum exceeded a level expected for the design basis earthquake S2, which is the expected maximum earthquake in the region, at a period of about $0.05 \mathrm{~s}$. Consequently, it is a serious issue why such large-amplitude short-period ground motions were observed for the $\mathrm{Mw}=7.2$ earthquake, which is smaller than

Copyright (c) The Society of Geomagnetism and Earth, Planetary and Space Sciences (SGEPSS); The Seismological Society of Japan; The Volcanological Society of Japan; The Geodetic Society of Japan; The Japanese Society for Planetary Sciences; TERRAPUB the expected one of about M7.5.

At the tip of the Oshika peninsula (shown by a solid triangle in Fig. 1), we initiated an array observation using seven strong-motion seismographs in April, 2004. The site of the Oshika array may be closest on land to the source area of the expected Miyagi-Ken-Oki earthquake. The strong-motion seismographs deployed at the Oshika array are the Kinemetrics Altus-K2 with a full-scale range of $\pm 2 g$, the records of which are sampled at a rate of $100 \mathrm{~Hz}$. Each seismograph is installed on a concrete base that is coupled to the ground by nine wooden pillars, each $80 \mathrm{~cm}$ long. The site is in a pasture. Although the geological structure of the site is identified as volcanic rock in Mesozoic (early Cretaceous andesite and dacite tuff-breccia and tuff) (Editorial Committee of Geologic Atlas of Japan, 1992), the shallow structure is not known since no geotechnical or geophysical logging and boring investigations have been carried out. The observation is mainly aimed to estimate the rupture propagation of the expected earthquake by the array analysis (e.g. Spudich and Cranswick, 1984; Goldstein and Archuleta, 1991). This approach will enable us to 'directly' estimate rupture propagation because we need not make any assumptions on the rupture velocity as used in the waveform inversion but use the velocity structure between the source and the receiver.

During the August 16, 2005 event, we succeeded in recording strong ground motions at six stations in the array, which is located about $70 \mathrm{~km}$ westerly-north-west from the epicenter. Only one station, OSK3, recorded $P$-waves but not $S$-waves part correctly because the anchor bolt became loose by the strong motion. Within 1 month after the mainshock, seismograms of ten aftershocks, whose epicenters are shown by open stars in Fig. 1, were also recorded. 

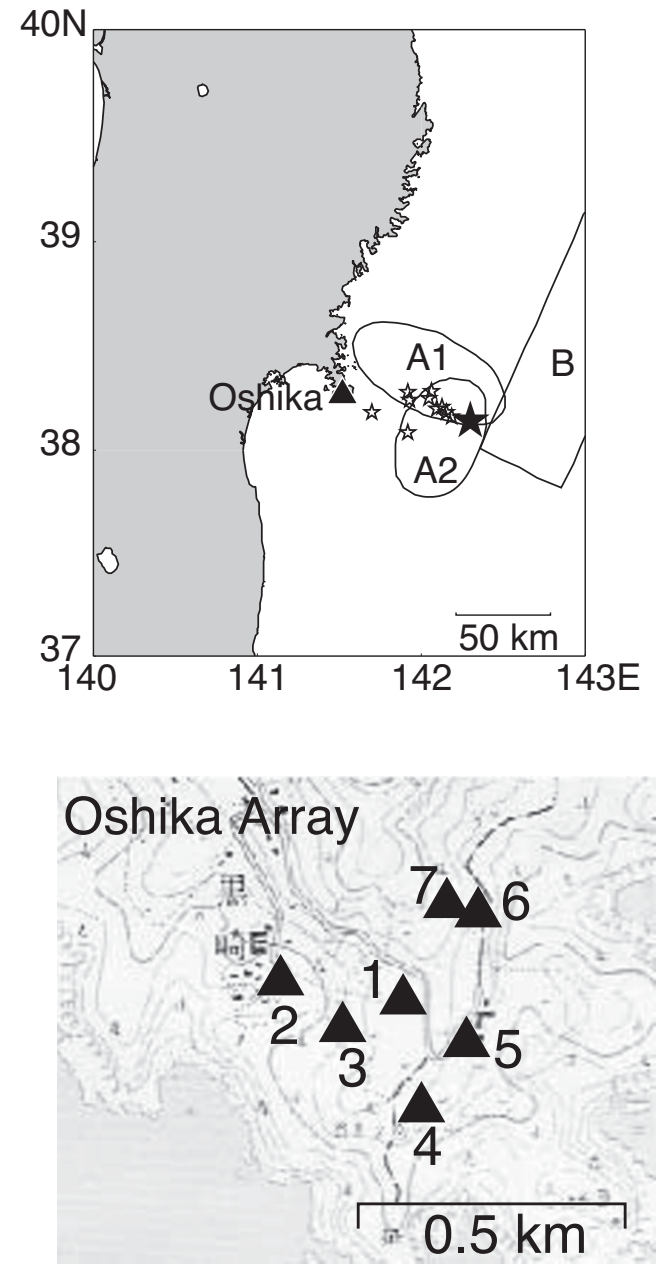

Fig. 1. The location of the Oshika array (solid triangle) and the epicenter of the August 16, 2005 Miyagi-Ken-Oki earthquake (solid star) and ten aftershocks (open stars). The regions A1, A2, and B are expected source regions of the expected Miyagi-Ken-Oki earthquake of M around 7.5. The lower map shows the configuration of stations in the Oshika array. This map is overwritten on the enlarged 1:25,000-scale topographical map of 'Kinkasan' issued by the Geographical Survey Institute of Japan. There are seven stations constituting the Oshika array. A number is appended to each station, as shown in the map. The station code is the character 'OSK' and the number (e.g., OSK2 for the number of 2).

Table 1. Peak ground acceleration (PGA) and peak ground velocity (PGV).

\begin{tabular}{crrrrrr}
\hline & \multicolumn{3}{c}{ PGA $\left(\mathrm{cm} / \mathrm{s}^{2}\right)$} & \multicolumn{3}{c}{ PGV $(\mathrm{cm} / \mathrm{s})$} \\
\cline { 2 - 7 } Station & \multicolumn{1}{c}{ EW } & \multicolumn{1}{c}{ NS } & \multicolumn{1}{c}{ UD } & EW & NS & \multicolumn{1}{c}{ UD } \\
\hline OSK1 & 557.0 & 625.9 & 331.5 & 16.91 & 25.69 & 7.55 \\
OSK2 & 1365.1 & 1747.6 & 869.1 & 32.35 & 41.81 & 12.75 \\
OSK4 & 987.9 & 1015.2 & 534.3 & 23.90 & 24.97 & 12.23 \\
OSK5 & 1353.9 & 1516.0 & 468.2 & 20.49 & 24.17 & 8.71 \\
OSK6 & 930.4 & 1102.4 & 368.7 & 17.10 & 19.76 & 6.66 \\
OSK7 & 572.5 & 867.2 & 465.0 & 17.40 & 11.05 & 9.31 \\
\hline
\end{tabular}

Because it is rare to record strong ground motions in such a small area, the data provide rare opportunity to clarify the spatial variation of ground motions.

The purpose of this article is to summarize the characteristics of observed strong ground motions during the events
(a)EW

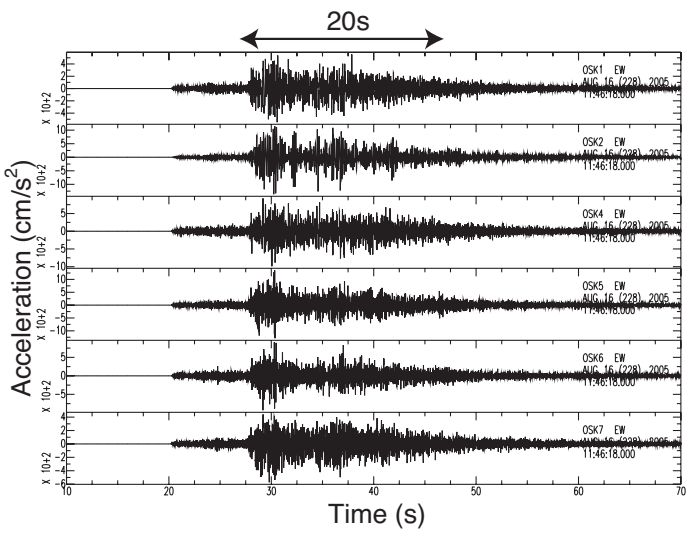

(b) NS

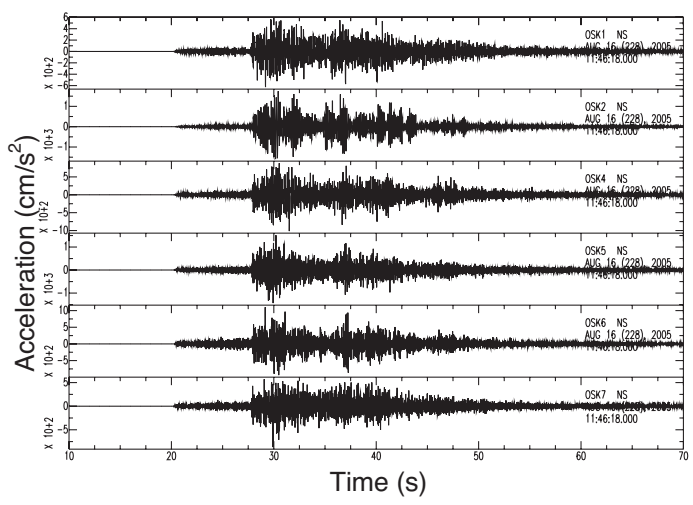

(c) UD

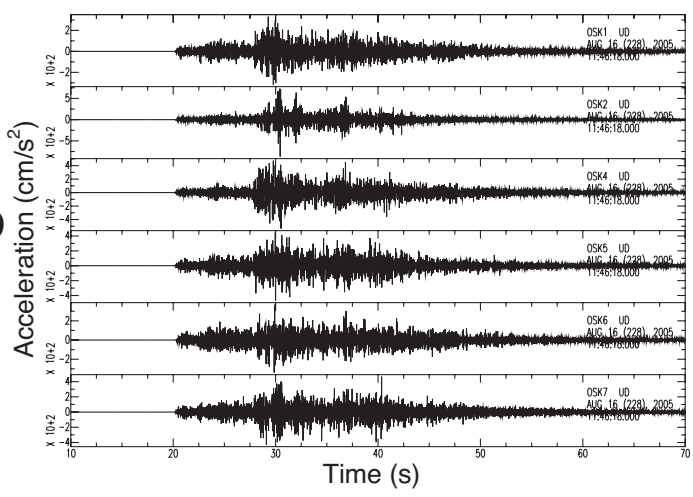

Fig. 2. Acceleration records at six stations in the Oshika array. (a) EW, (b) NS, (c) UD component. Eastward, northward, and upward motions are positive in all the traces.

in terms of acceleration records, acceleration Fourier spectra, velocity response spectra, spectral ratio between station pairs, and the similarity of waveforms among the stations. In addition, this study may help researchers gain an understanding of just to what degree the difference in site conditions contributed to the large-amplitude ground motions in Oshika peninsula caused by the August 16, 2005 event.

\section{Strong Ground Motions Observed at the Os- hika Array}

East-west (EW), north-south (NS), and vertical (UD) components of the observed acceleration records for $60 \mathrm{~s}$ are shown from top to bottom in Fig. 2. Baseline correction is applied to all the records. The shape of the waveforms is not similar between the stations, although the distance between stations is only about $150 \mathrm{~m}$ on average. Large- 
(a) EW

$$
\text { क) }
$$
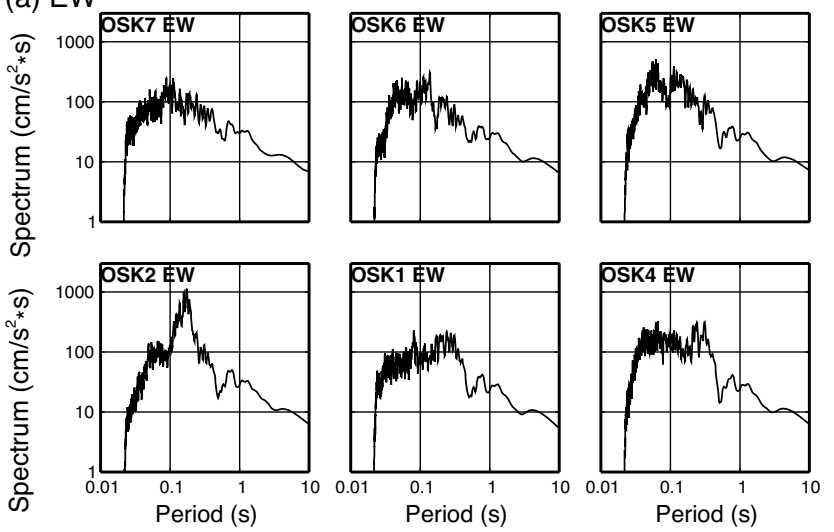

(b) NS
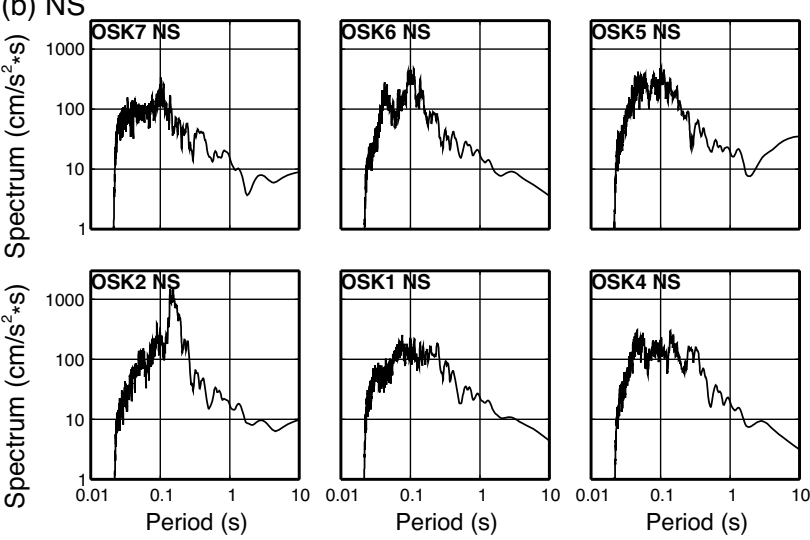

(c) UD
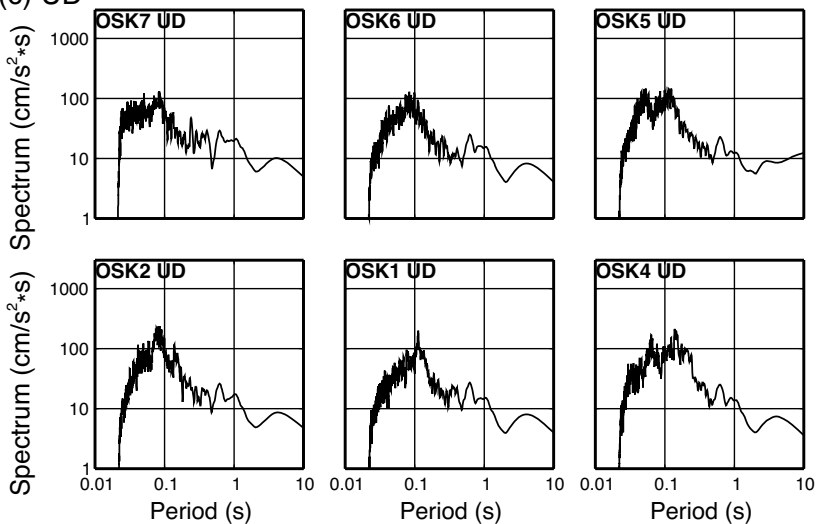

Fig. 3. Acceleration Fourier spectra for 20-s-long $S$-waves of the mainshock. (a) EW, (b) NS, (c) UD component.

amplitude motions continue for about 20 s after the $S$-wave arrival. Several peaks are found for the envelope shapes. The peak ground acceleration (PGA) and the peak ground velocity $(\mathrm{PGV})$ are enumerated in Table 1 . Each PGV is read from a velocity record calculated by the integration of an acceleration record and by filtering out periods longer than $10 \mathrm{~s}$. Residual displacement is not easy to be recovered from the double integration of our acceleration records, although coseismic displacement of $5.6 \mathrm{~cm}$ eastward and $4.9 \mathrm{~cm}$ downward was detected at a Global-PositioningSystem station in the same peninsula for the event (Geographical survey institute, 2006). Stations OSK2, OSK4, OSK5, and OSK6 recorded PGA larger than $1 \mathrm{~g}$. The maximum PGA exceeded $1.7 \mathrm{~g}$ for the NS-component record

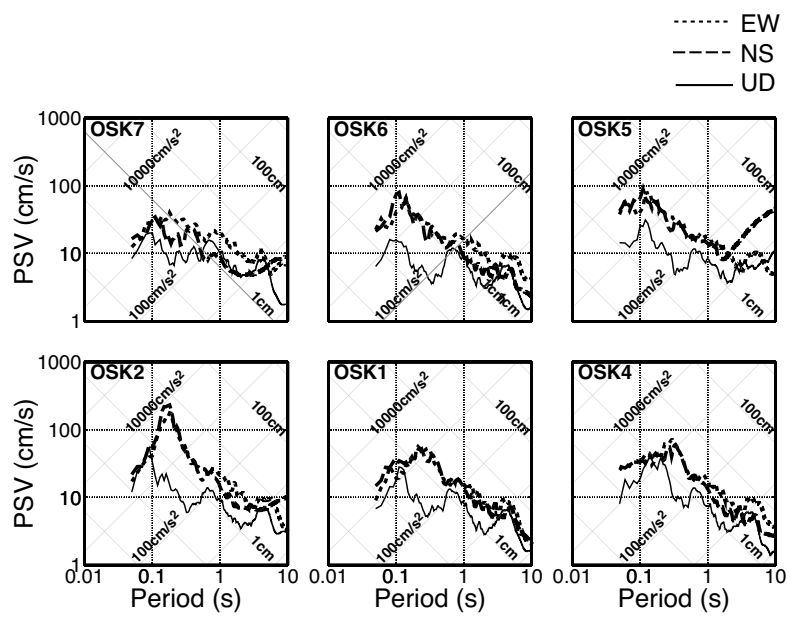

Fig. 4. Pseudo-velocity response spectra with 5\% damping. Dotted, broken, and solid curves stand for the results for the EW, NS, and UD component, respectively.

at OSK2, while it was smaller than $1 g$ at stations OSK1 and OSK7. PGA varies among the stations by up to approximately threefold. At station OSK2, PGV also reached $40 \mathrm{~cm} / \mathrm{s}$. The PGV also shows approximately a threefold variation among the stations.

Figure 3 shows acceleration Fourier spectra for the $S$ wave part. The $S$-wave part is chosen here as the 20 -slong time window starting from $1 \mathrm{~s}$ before the $S$-wave onset shown by an arrow in Fig. 2. To calculate the spectra, we first calculate power spectra for time windows of $40.96 \mathrm{~s}$ in which the $S$-wave seismograms of $20 \mathrm{~s}$ and trailing zeros are included. The cosine taper is applied to both $5 \%$ ends of the $S$-wave data. The power spectrum is smoothed by operating the Hanning window ten times, and the square root of the power spectra is calculated. The results reveal that amplitudes at periods shorter than about $0.2-0.3 \mathrm{~s}$ are predominant at all stations. We also find that the shape of the spectra varies from station to station. At station OSK2, it is remarkable that a narrow peak exists at a period of about $0.15 \mathrm{~s}$ and that the amplitude of the peak is up to tenfold larger than that of other stations. This peak is prominent on the horizontal components. The large PGA and PGV at this station can be attributed to the peak. The characteristics of the NS and UD components at station OSK5 are different from those at other stations in periods longer than $2 \mathrm{~s}$. These are due to long-period noise, but the origin is not clear.

The pseudo-spectral velocity (PSV; or pseudo-velocity response spectrum) with 5\% damping are shown in Fig. 4. The response spectrum shows the maximum amplitude (acceleration or velocity or displacement) of a damped oscillation of a single-degree-of-freedom pendulum with a certain natural frequency subjected to an input earthquake ground acceleration The results for EW, NS, and UD are shown in dotted, broken, and solid curves, respectively. The variation in the PSV among the stations is large in shorter periods and small in longer periods. Two horizontal components generally show similar response spectra. At station OSK2, the amplitude of PSV is up to $200 \mathrm{~cm} / \mathrm{s}$ at a period of about $0.15 \mathrm{~s}$, corresponding to the sharp peak in the acceleration 

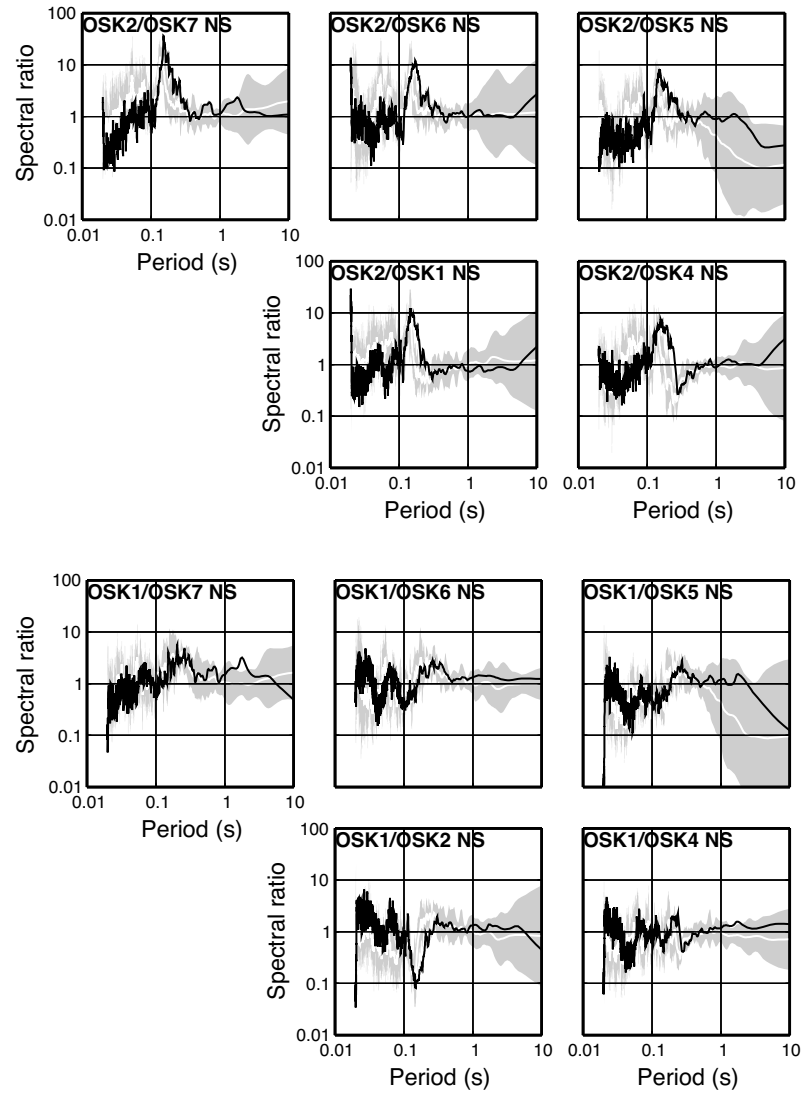

Fig. 5. Spectral ratio between pairs of the stations in the Oshika array. Results for NS components are shown. Spectral ratios for the mainshock are drawn by thick solid curves. Average and \pm 2 SD of the spectral ratio for ten aftershocks are shown by white solid curves and shaded regions, respectively.

Fourier spectrum. In contrast, the PSV at around $1 \mathrm{~s}$ is about $10 \mathrm{~cm} / \mathrm{s}$. In such a case, the damage to buildings may be small despite the large PSA and PSV, as suggested by Sakai et al. (2004).

\section{Discussion}

\subsection{Spectral ratio between stations}

We have considered the spectral ratio between two stations for a certain event. Since the aperture of the array is about $500 \mathrm{~m}$, the effect of the source and the propagation path is considered to be the same for all the stations in the array. Consequently, we can estimate the difference in the site amplification factor of two stations by taking the spectral ratio between the stations. We calculate the spectral ratio between each station pair for the mainshock as well as for ten aftershocks. The epicenter of the aftershocks is shown by open stars in Fig. 1.

Power spectra for the aftershocks are calculated in the same manner as for the mainshock except that the $S$-wave part is chosen as 10-s-long time window starting $0.5 \mathrm{~s}$ before the onset of the $S$-wave. The spectral ratio is calculated from the square root of the power spectra for the mainshock and the aftershocks. Some of the calculated spectral ratio are shown in Fig. 5. A thick solid curve is the result for the mainshock and a solid white curve is the average for ten aftershocks. A shaded region stands for \pm 2 SD for the ten (a) Original

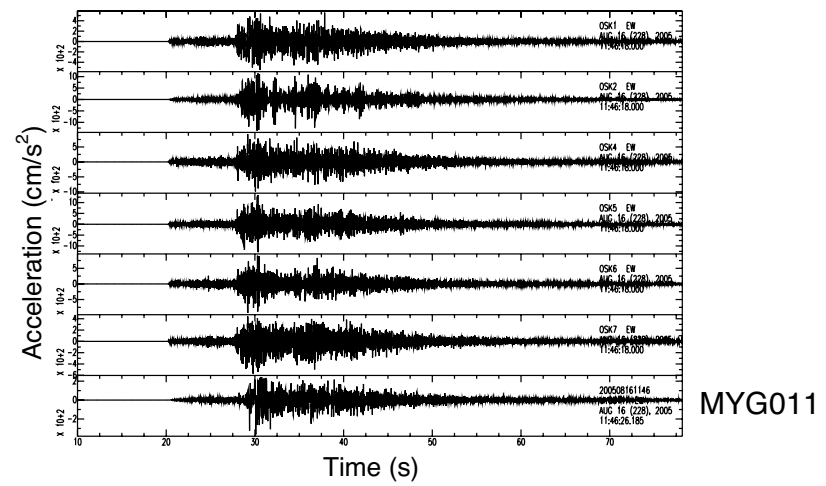

(b) $1-10 \mathrm{~s}$

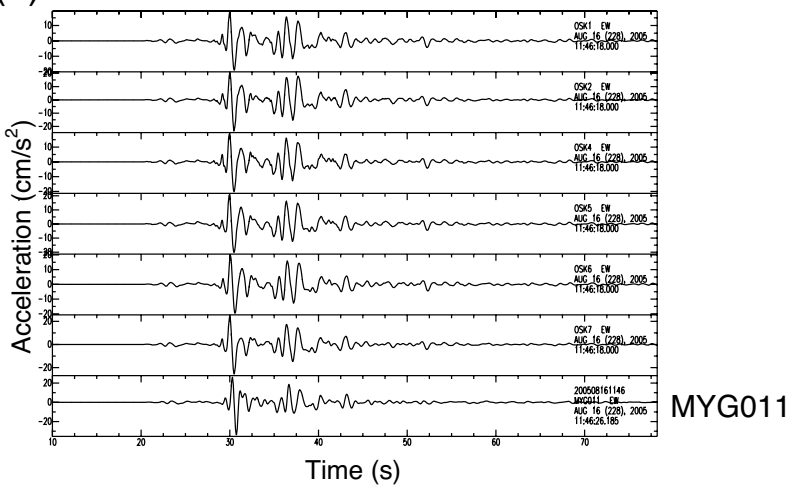

Fig. 6. Spatial variation of strong ground motions. In addition to the records at six stations in the array, the record at the station MYG011 is shown in the bottom. (a) original acceleration records, (b) band-passed acceleration records in a period band from 1 to $10 \mathrm{~s}$.

aftershocks. For the station pairs including station OSK2, the value of the spectral ratio is up to ten at a predominant period of about $0.15 \mathrm{~s}$. The predominant period seems to become longer for the mainshock than for the ten aftershocks. However, we can not find the difference in the amplitude of the spectral ratio at the period between the mainshock and the aftershocks. For station pairs not including OSK2, we can not find any significant shift in the predominant period. As such, we can point out that the nonlinear site response (e.g., Field et al., 1997) may occur at the station OSK2 during the mainshock. For all station pairs, the amplitude of the spectral ratio is around one for periods from about 0.5 to $2 \mathrm{~s}$. In longer period ranges, the range of the $\pm 2 \mathrm{SD}$ for the aftershocks is large, possibly because the spectra for the aftershocks are contaminated by noises.

\subsection{Implications for the spatial variation of strong ground motions}

About $2 \mathrm{~km}$ north from the array, there is a strong-motion station MYG011 of the K-NET, NIED. To observe the spatial variation of ground motions, we compare the strongmotion record of the mainshock at this station with those at the array. In Fig. 6(a) shows the original acceleration records. The bottom trace is for station MYG011, and the difference between this station and the others is clear. However, when we perform a band-pass filter in a period ranging from 1-10 s, we obtain records that are similar among all the stations, as shown in Fig. 6(b). Therefore, the similarity 
in the waveform is found even at longer station separations for longer periods (or lower frequencies). Among records at the stations in the array, we confirmed the waveform similarity down to a period of $0.4 \mathrm{~s}$. Therefore, we suggest using the array analysis techniques such as the beam-forming within the period range.

\section{Conclusions}

We have succeeded in recording strong ground motions at a near-source seismographic array during the August 16, 2005 Miyagi-Ken-Oki earthquake. Analyzing the records, we have clarified the following characteristics:

(1) PGA is more than $1 \mathrm{~g}$ at four stations among the six operational. The largest PGA exceeds $1.7 \mathrm{~g}$ at station OSK2.

(2) Components with periods shorter than about $0.3 \mathrm{~s}$ are predominant.

(3) Short-period ground motions show a large spatial variation, with up to a tenfold difference in amplitude within the array with an aperture of only $500 \mathrm{~m}$.

(4) Waveform similarity is found between stations in the array for periods longer than $0.4 \mathrm{~s}$.

(5) The non-linear site response may have occurred at station OSK2 during the mainshock.

It is necessary to clarify the velocity structure beneath the stations to understand why ground motions with such a large amplitude and such large spatial variation were generated in the array. The irregular topography at the array certainly contributes to the spatial variation. However, topographical change has an effect of at most a factor of two on the spatial variation of ground motion, and may have a smaller effect than the subsurface velocity structure (e.g., p. 252, Architectural Institute of Japan, 2005). Because the application of the array analysis to records is possible in the longer periods, it is suggested that we may detect the rupture propagation of the mainshock as the change of azimuth and incident angles to the array from the source. In addition, the probability of the occurrence of the expected Miyagi-Ken-Oki event still remains high. We should continue the array observation to capture the strong ground motions from the pending expected event.
Acknowledgments. We are very grateful to Mr. Tokushichi Ito and Mr. Keiki Kuchiki for permitting us to use a part of their pasture for our seismographic array observation. We used the hypocenters determined by Research Center for Prediction of Earthquakes and Volcanic Eruptions, Tohoku University and Japan Meteorological Agency. Constructive review comments from Prof. Naoshi Hirata, Mr. Tomiichi Uetake, and Dr. Artak Martirosyan are greatly acknowledged. A part of this observation was supported by the 21 st century COE program "Advanced Science and Technology Center for the Dynamic Earth" of Tohoku University. The GMT software (Wessel and Smith, 1998) was used for making figures.

\section{References}

Architectural Institute of Japan, Jiban Shindou-Genshou to Riron, Architectural institude of Japan, Tokyo, 2005 (in Japanese).

Editorial committee of geologic atlas of Japan, Geologic atlas of JapanTohoku region, Asakura Shoten, Tokyo, 1992.

Field, E. H., P. A. Hohnson, I. A. Beresnev, and Y. Zeng, Nonlinear groundmotion amplification by sediments during the 1994 Northridge earthquake, Nature, 390, 599-602, 1997.

Geographical Survey Institute, Crustal movements in the Tohoku district, Rep. Coord. Comm. Earthq. Pred., 75, 75-114, 2006 (in Japanese with English figure captions).

Goldstein, P. and R. Archuleta, Deterministic frequency-wavenumber methods and direct measurements of rupture propagation during earthquakes using a dense array: Data analysis, J. Geophys. Res., 96, 61876198, 1991.

Sakai, Y., T. Kanno, and K. Koketsu, Proposal of instrumental seismic intensity scale from response spectra in various period ranges, J. Struct. Constr. Eng., AIJ, 585, 71-76, 2004.

Spudich, P. and E. Cranswick, Direct observation of rupture propagation during the 1979 Imperial Valley, California, earthquake using a short baseline accelerometer array, Bull. Seismol. Soc. Am., 74, 2083-2114, 1984.

The headquarters for earthquake research promotion (HERP), List of long-term evaluation, (web address: http://www.jishin.go.jp/main/ choukihyoka/kaikou.htm), 2005 (only in Japanese).

Wessel, P. and W. H. F. Smith, New improved version of the Generic Mapping Tools released, EOS Trans., Am. Geophys. Union, 79, 579, 1998.

H. Nakahara (e-mail: naka@zisin.geophys.tohoku.ac.jp), K. Sawazaki, N. Takagi, T. Nishimura, H. Sato, and H. Fujiwara 